\title{
REVIEW
}

Open Access

\section{Change in psychosocial factors connected to coping after inpatient treatment for substance use disorder: a systematic review}

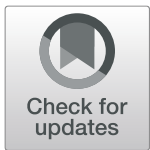

Dagny Adriaenssen Johannessen ${ }^{1,3^{*}} \mathbb{D}$, Trond Nordfjærn ${ }^{2}$ and Amy Østertun Geirdal ${ }^{3}$

\begin{abstract}
Background: Among the adult population worldwide, about 0.5\% has illicit drug use disorder (DUD) and about 5\% has alcohol use disorder (AUD). Dependency on alcohol, medication or illicit drugs are recognised as risk factors for disabling disease and early death. Treatment for substance use disorders (SUD) is important in promoting persistent abstinence and may be perceived as a valuable public health measure. The current systematic review aims at exploring how psychosocial factors connected to recovery capital and coping behaviour, change after inpatient SUD treatment.

Methods: A systematic search was conducted in Campbell Collaboration Library, Cochrane Library, EMBASE, Epistemonikos, Medline, PsychINFO, Social Sciences Citation Index and SocINDEX. Cohort studies on psychosocial outcomes for adults who had attended to inpatient SUD treatment that exceeds 3 months, were included. The outcome of interest was change in psychosocial factors. The search results were identified as include, exclude or unclear by one author and then screened by the second author with a specific focus on studies recognised as unclear. Diverging evaluations of eligibility among the unclear studies were resolved by discussion. In case of disagreement, the third author decided the eligibility of the studies in question.
\end{abstract}

Results: Findings imply an overall progress in mental health, and a potential improvement in employment status and perceived social support after inpatient SUD treatment. Additionally, findings indicate a decrease in substance use from admission to follow-up after discharge from inpatient SUD treatment. These findings are consistent with earlier research on important factors in recovering from SUD. Findings on change in self-efficacy, housing, education and Quality of Life (QoL) however, were scantly researched and were expected to be more prominent outcomes of interest among the included studies.

Conclusion: Due to the substantial resources used to provide SUD treatment, knowledge about recovery capital, like psychosocial factors that facilitate coping behaviour and reintegration to society, should be standardised and used by SUD treatment providers.

Trial Registration: PROSPERO registration ID: CRD42018087408

Keywords: Substance-related disorders, Residential treatment, Treatment outcome, Follow-up study, Social adjustment, Recovery capital

\footnotetext{
*Correspondence: dagnjo@oslomet.no

${ }^{1}$ Blue Cross East, Oslo, Norway

${ }^{3}$ Faculty of Social Sciences, Department of Social Work, Child Welfare and

Social Policy, OsloMet - Oslo Metropolitan University, Pb 4, St. Olavs plass,

0130 Oslo, Norway

Full list of author information is available at the end of the article
}

(c) The Author(s). 2019 Open Access This article is distributed under the terms of the Creative Commons Attribution 4.0 International License (http://creativecommons.org/licenses/by/4.0/), which permits unrestricted use, distribution, and reproduction in any medium, provided you give appropriate credit to the original author(s) and the source, provide a link to the Creative Commons license, and indicate if changes were made. The Creative Commons Public Domain Dedication waiver (http://creativecommons.org/publicdomain/zero/1.0/) applies to the data made available in this article, unless otherwise stated. 


\section{Background}

About $5 \%$ of the adult population worldwide have used illicit drugs at least once within the previous year. Approximately $10 \%$ of these individuals have drug use disorder [1]. Records from 2014 reveal that more than 200.000 people suffered a drug-related early death worldwide that year, [2] a number which simply is too high. Additionally, half of the world's adult population have consumed alcohol during the prior year, and more than $5 \%$ of the world's population have alcohol use disorder. Alcohol consumption is identified as one of the leading risk factors for disabling disease and shortening of life and represent one of the most prevalent causes of death worldwide [3]. On this background treatment for substance use disorder (SUD) may be perceived as a valuable public health measure [1].

Substantial resources are used internationally to provide treatment for SUD, substitution treatment and to treat SUD-related health problems [4]. Still, it is estimated that more than half relapse to substance use in the time after discharge from SUD treatment [5-7], even if relapse does not necessarily mean that the individual proceeds to use the same amount(s) of substance(s) as pre-treatment [8]. In the 10th edition of the International Statistical Classification of Diseases and Related Health Problems (ICD-10), SUD is described as "a cluster of physiological, behavioural, and cognitive phenomena in which the use of a substance or a class of substances takes on a much higher priority for a given individual than other behaviours that once had greater value" (p. 75) [9].

Some scholars have advised against comparing different treatment modalities with each other [10], and conclude that change in psychosocial function tends to occur regardless of modality $[11,12]$. For instance, findings from extensive prospective cohort studies of patient outcome after SUD treatment such as the Drug Abuse Treatment Outcome Study (DATOS), Treatment Outcome Prospective Study (TOPS) and National Treatment Outcome Research Study (NTORS), show a clear reduction of substance use after completed treatment [10, 13-18]. Inpatient SUD treatment is considered to be important in promoting persistent abstinence [19] as well as personal, social and environmental change [1].

Much is known about psychosocial factors that facilitates recovery capital and increase the ability to cope in everyday life without substance use. Here, psychosocial factors refer to aspects which are currently conceptualized within the term recovery capital, like social support, housing, meaningful activity (e.g. employment and education), mental health and Quality of Life (QoL). Recovery capital can be described as individual or environmental attributes which facilitate the ability to recover from SUD, such as coping behaviour, and personal, structural and social resources [20-23]. Coping behaviour, which is embraced by recovery capital, is understood in line with Neale [24], as "managing negative feelings and bodily changes rather than trying to prevent them from occurring" (p. 32). Coping, thus, involves responses or actions taken in a given situation, or, coping behaviour [25]. Examples of facilitating psychosocial factors are social support and housing [24, 26-31], employment and education $[6,24,26-28,30,32]$, treatment completion and commitment to continued care discharge plans [27, 32, 33]. However, these findings are mostly related to recovering from substance abuse after outpatient treatment, inpatient treatment with a duration of less than 3 months (short-term), peer-support or no treatment, while we know less about change in psychosocial factors after inpatient SUD treatment exceeding 3 months (long-term). Even if long-term inpatient SUD treatment is uncommon in some parts of the world, previous research suggests a better treatment outcome related to protective psychosocial factors, behaviour and maintained abstinence from substance use when comparing short-term with long-term SUD treatment [16, 34-38]. Additionally, long-term inpatient SUD treatment has been recognised as one of the most common modalities $[39,40]$, and has traditionally been included in extensive treatment outcome studies in the United States and Europe (see e.g. [10, 41-44]). We know less about SUD treatment duration in developing countries, even though SUD appears to be a widespread issue of concern [45].

To our knowledge, there are no systematic reviews to date that have aimed at exploring how psychosocial factors connected to recovery capital, change after long-term inpatient SUD treatment. This study originally aimed at exploring psychosocial factors associated with coping after inpatient SUD treatment. During the analysis process, however, we discovered that the findings also could provide information about change in psychosocial factors after inpatient SUD treatment. Therefore, the current systematic review aims to use findings from the systematic search to explore the following research question:

How do psychosocial factors connected to coping, change after inpatient treatment for substance use disorder?

\section{Methods}

The overarching objective of a systematic review is to gather, unify and summarise research findings in the purpose to synthesise a new body of knowledge [46]. The current systematic review takes form as a thematic summary and purposes to outline overall findings by exploring differences and similarities among findings from the included studies. The systematic search bases on more or less pre-defined concepts except the sought outcome, namely the psychosocial factors. The search was designed with the purpose of allowing multifarious 
psychosocial factors to emerge among the results. The reason for this broad approach was that we wanted to also reveal studies about psychosocial factors that potentially could contribute to elucidate the current aim. The purpose of this review is to generate a body of knowledge about change in psychosocial factors enabling coping behaviour in everyday life after inpatient SUD treatment. Findings will be structured and presented in line with characteristics of the extracted findings from the included study reports.

\section{Search strategy}

A set of text words (see Additional file 1) was developed by determining the Population, Exposure and Outcome (PEO) [47] of interest, and by exploring definitions, keywords, and indexing of related studies. Based on the included text words, subject headings (see Additional file 2) were identified in each of the included databases, which will be outlined below. Together, the combination of text words and the database-specific subject headings constitute the search string (see Additional file 3) used in the systematic search.

The aim of this review is situated in an intersection point between two research fields; medicine/health and social sciences. Therefore, and because the chosen databases should reflect research that is desirable to explore the aim of interest, the selected databases have their main focus in the field of medicine/health and/or social sciences. A comprehensive search was conducted in Campbell Collaboration Library, Cochrane Library, EMBASE, Epistemonikos, Medline, PsychINFO, Social Sciences Citation Index and SocINDEX. To increase the probability of detecting eligible studies that were not embraced by these databases, a citation search was undertaken in Web of Science. Additional screening for eligible studies was performed within the first 100 hits from an advanced search, using the established set of text words, in Google Scholar (reported as other sources in Fig. 1). To ensure a satisfying quality, the current review has been conducted and reported according to the Preferred Reporting Items for Systematic Reviews and Meta-Analyses (PRISMA) [48].

\section{Procedure}

The search results were combined and controlled for duplicates using EndNote X8. One author (DAJ) eliminated irrelevant studies by screening titles and abstracts. After the first screening, the remaining studies were identified as include, exclude or unclear by the same author (DAJ), and then screened by the second author (TN) with a specific focus on studies which were recognised as unclear. Diverging evaluations of eligibility among the unclear studies were resolved by discussion.
In case of disagreement, the third author (AØG) decided the eligibility of the unclear studies.

The authors developed and pre-piloted a form to extract data of interest from the eligible studies. The relevance of the included studies was evaluated by one author (DAJ), using the Critical Appraisal Skills Programme (CASP) [49] 12-point checklist tool, developed to evaluate quality and relevance of included cohort studies. CASP is not recommended as a tool to report the quality-score [49] and has therefore not been further included in the results or discussion.

In cases where an eligible study did not report the data of interest to the current review, the corresponding author was contacted to obtain their opinion. This became applicable in four studies [50-53]. Three of the corresponding authors did not respond within 14 days, and the third author (AØG) determined the eligibility of these studies.

\section{Primary and secondary outcome}

The outcome of interest was change in psychosocial factors (e.g. social support, employment, mental health or QoL) after inpatient SUD treatment. Measures revealing prevalence of continued substance use after discharge are considered as the secondary outcome of interest. The reason for this was twofold and partly because the SUD population that are referred to inpatient treatment often strives with multiple psychosocial challenges, comorbidity and to handle everyday life [54-57], and rarely only strives with dependency on substances. Change in psychosocial factors after inpatient SUD treatment has been acknowledged as a valid measure for treatment outcome [1], which also was an important reason for primarily focusing on psychosocial factors.

\section{Inclusion criteria}

The results from the systematic search were screened and evaluated for eligibility based on the following pre-determined criteria. Population: adult men and women who were 18 years or older. Exposure: inpatient SUD treatment with a treatment duration exeeding 3 months. Outcome: various psychosocial factors. Study design: cohort studies with one or more follow-up measures after discharge from the index treatment. Reporting: peer reviewed study reports published in English. The systematic search was conducted without specific timespan-restrictions.

The reason for excluding studies exploring short-term inpatient treatment was the considerable resources used to provide SUD inpatient treatment [4], and that previous research has shown a positive correlation between long-term treatment and a favourable treatment outcome $[16,58]$. This correlation can, however, occur as a result of the extended treatment duration and the 


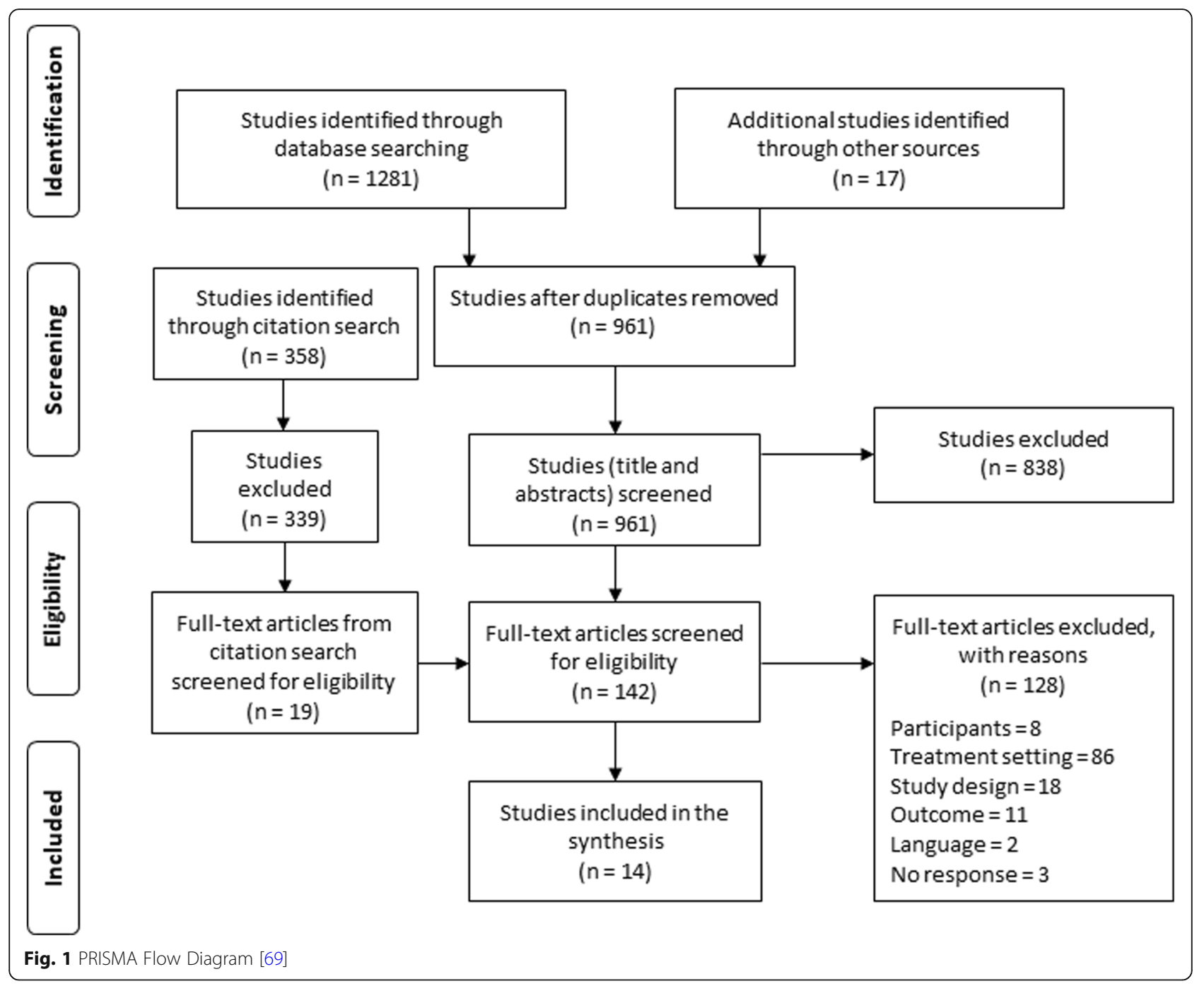

opportunity this gives for more detailed observations. The reason for excluding outpatient treatment was to reach studies with a SUD population that strives with multiple psychosocial challenges and comorbidity, and who struggles to handle everyday life (e.g. attending appointments, living at home, attend to work or activity, maintain daily routines), which often is the case for those who are referred to inpatient treatment [54-57]. Additionally, previous systematic reviews and meta-analyses have already summarised effect-studies of various outpatient treatments and services [59-63]. Inpatient SUD treatment is considered to be important in promoting persistent abstinence [19] as well as personal, social and environmental change [1]. Inpatient SUD treatment can be described as interventions and measures aiming to alter conditions leading to destructive conditions and corroborate behaviour that reduces problematic substance use, which takes place at a treatment facility where the patient is a resident [64].
A comparison or control group was not a methodological requirement for inclusion in this review. A considerable degree of the treatment outcome research in the SUD field are observational naturalistic studies (see e.g. $[10,17,36,41,42,65])$. Even if comparing pre- and post-treatment measures involves some pitfalls, a randomised controlled study design is not necessarily a viable option when studying change in multifarious psychosocial factors after treatment [66-68]. Based on the mentioned issues, and as further narrowing of the eligibility criteria could reduce the probability of detecting studies that serve the mentioned purpose, we decided to include both studies with and without a comparison.

\section{Ethical statement}

The current target group, people with SUD, might be considered as vulnerable. On this background, this population was the group of interest a review of already conducted studies. Patients have not been involved in 
this study and an ethical approval has therefore not been sought.

The study was registered in PROSPERO (registration ID: CRD42018087408) in the planning stage and has been updated consecutively.

\section{Results}

\section{Identification}

The selection steps are presented in the PRISMA Flow Diagram [69] (see Fig. 1), where the listed inclusion criteria are arranged in the same order as reason for exclusion (1) participants, 2) setting, 3) study design, and 4) outcome). One thousand two hundred eighty-one studies were identified through the systematic search. Nine hundred forty-four studies remained after the duplicates were removed. Additionally, 375 studies were identified through Google Scholar and citation searches. In total, 1319 titles and abstracts were screened, whereupon the eligibility of 1177 (838 studies from the main search and 339 studies from the citation search) studies was determined. The remaining 142 studies were read in full-text. Finally, 14 studies were found to be eligible for inclusion. See Fig. 1 for a detailed list of reasons for exclusion after the full-text read through.

\section{Characteristics}

Characteristics of the included studies are summarised in Table 1. Findings related to change in psychosocial factors after inpatient SUD treatment, are presented in Table 2.

Mainly, the included studies were conducted in the United States $(n=10)$. However, Belgium $(n=1)$, Greece $(n=1)$ and Switzerland $(n=1)$ were represented as well. One of the studies did not report the country in which it was carried out. The systematic search sought for studies which were published until the time of the search (February 2018). However, findings revealed that data used in the eligible studies had been collected from 1974 [70] to 2009 [71], and the last point of follow-up ranged from 3 months to 5 years post-discharge. The total sample size at baseline was at least 7.384 participants. Two of the studies $[16,72]$ did not report the sample size at baseline. All the included studies reported sample size at follow-up after discharge, which was calculated to be a total of 4.674 participants. The mean (M) percentage of loss to follow-up among the 12 studies that reported sample size at both baseline and follow-up, was $39 \%$ (median $(\mathrm{Mdn})=37 \%)$. Primarily, the included studies had employed a pre-post cohort design. However, four studies [16, 73-75] used a comparative design where change in one group was compared to changes in another group that had received a different intervention. All the 14 included studies had a quantitative methodological orientation.
Unless specified otherwise, reported psychosocial change in Table 2 applies to the change from baseline to the last measure point at follow-up.

None of the studies reported effect sizes (Cohen's d) and few studies reported the $M$ and standard deviation (SD) at baseline and follow-up. It was therefore not an option to include Cohen's d consistently when reporting the findings in this review. The authors of the current review calculated Cohen's $d$ in studies that reported $M$ and SD at both baseline and follow-up [72, 76]. These results are presented in Table 2. Only one study reported Confidence interval (CI) [77]. Accordingly, it was not viable to undertake and include a meta-analysis in this review. An overall statistical analysis has therefore not been provided in the findings presented hereunder.

In addition to what was defined as secondary outcome, potential change in six psychosocial factors related to recovery capital and coping behaviour were identified and will be described separately in the following sections.

\section{Mental health}

The most studied psychosocial factor throughout the included studies was different versions of mental health (e.g. anxiety, depression, self-efficacy, psychological distress), which represented 15 outcomes in eight studies [71, 72, 75-80]. Mental health has been defined as personal, environmental or social properties which facilitates a person's well-being and ability to recover and contribute to and take part in society [81]. Across the included studies, findings suggested a decrease in the following factors; depression and anxiety [71, 78], psychological distress [76, 77], PTSD-symptoms [72] and mental health problems [71, 79]. Findings further suggested an increase in the following factors; self-efficacy, perception of the meaning of life, positive emotion [71] and psychological health [75]. Additionally, one study [80] suggested that continued substance use was positively correlated with lower QoL at follow-up. Another study [77] suggested that self-efficacy at admission was predictive for abstinence at follow-up after inpatient SUD treatment. Self-efficacy has been recognised by Bandura [82] as a person's confidence in its own ability to reach a goal.

Findings across these studies suggest an overall increase in mental health and a decrease in mental health problems from admission to follow-up after inpatient SUD treatment.

\section{Education and employment}

Six studies reported findings related to change in employment status at follow-up after inpatient SUD treatment. Four studies $[16,70,78,83]$ presented change in percentage of which the $M$ increase in employment rates from admission to follow-up after inpatient SUD 


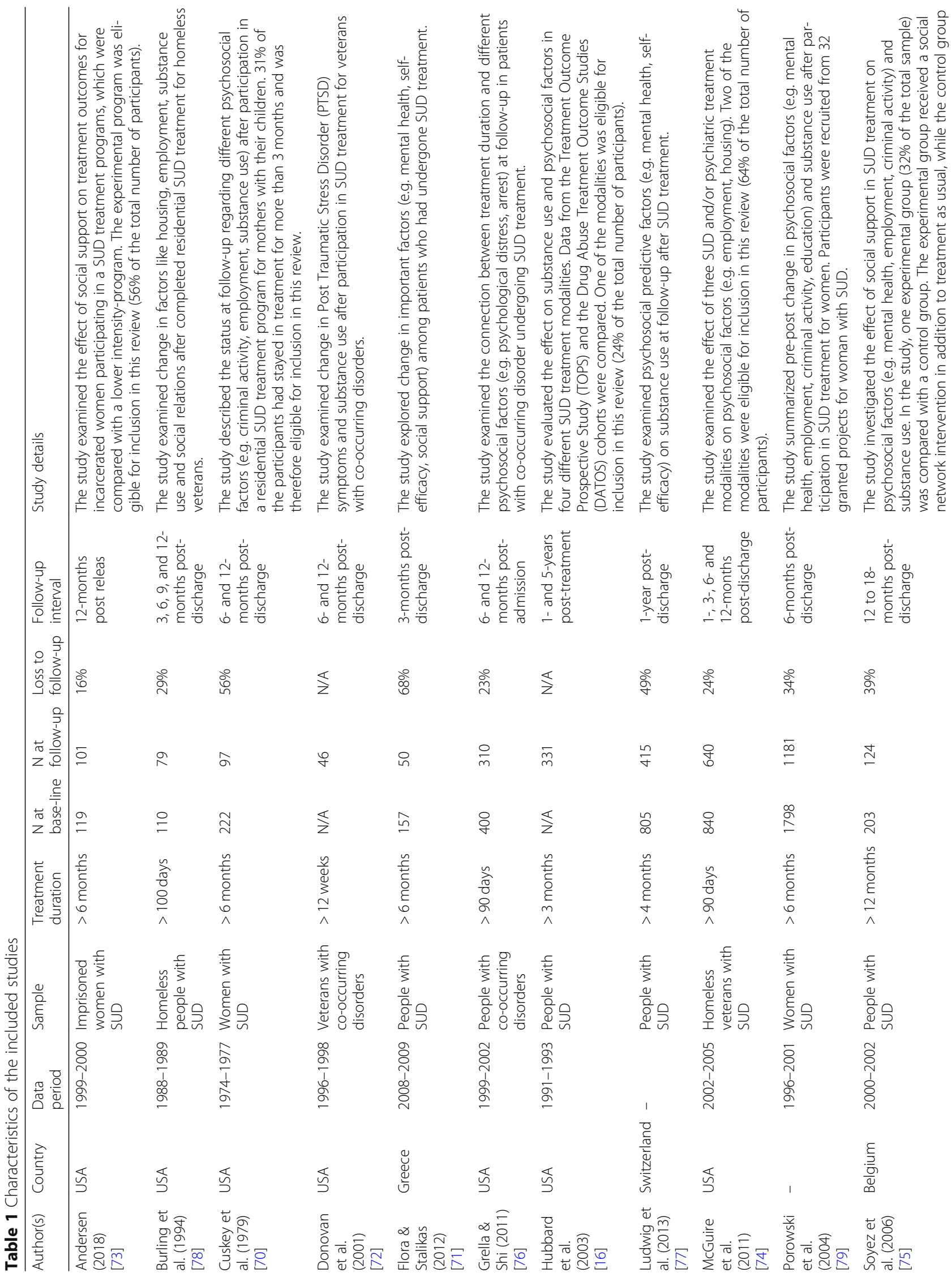




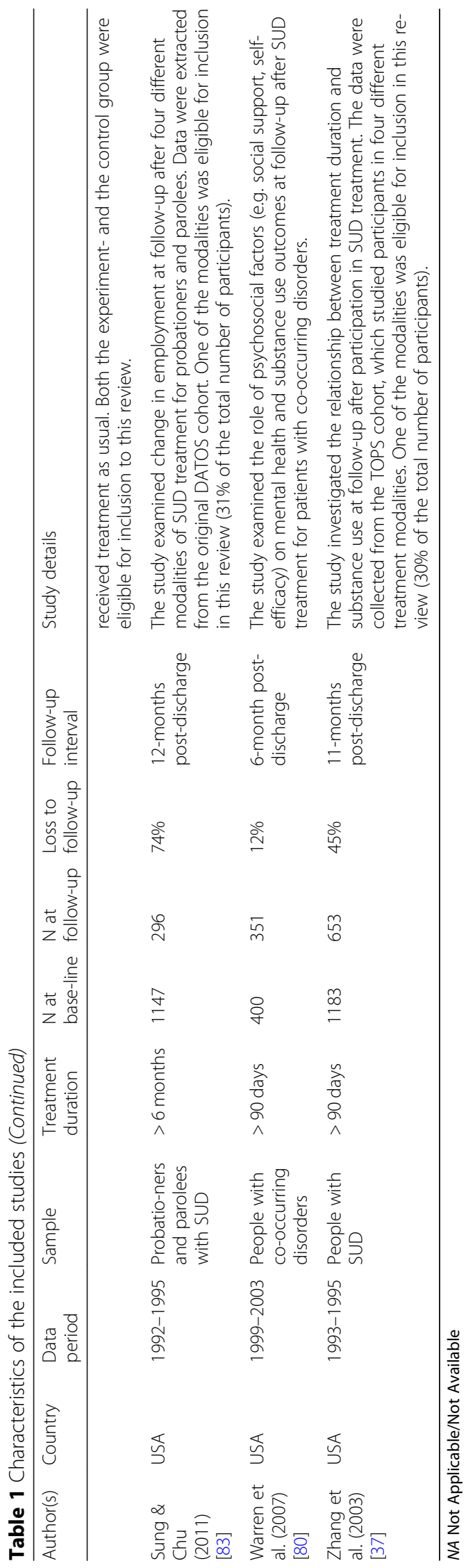




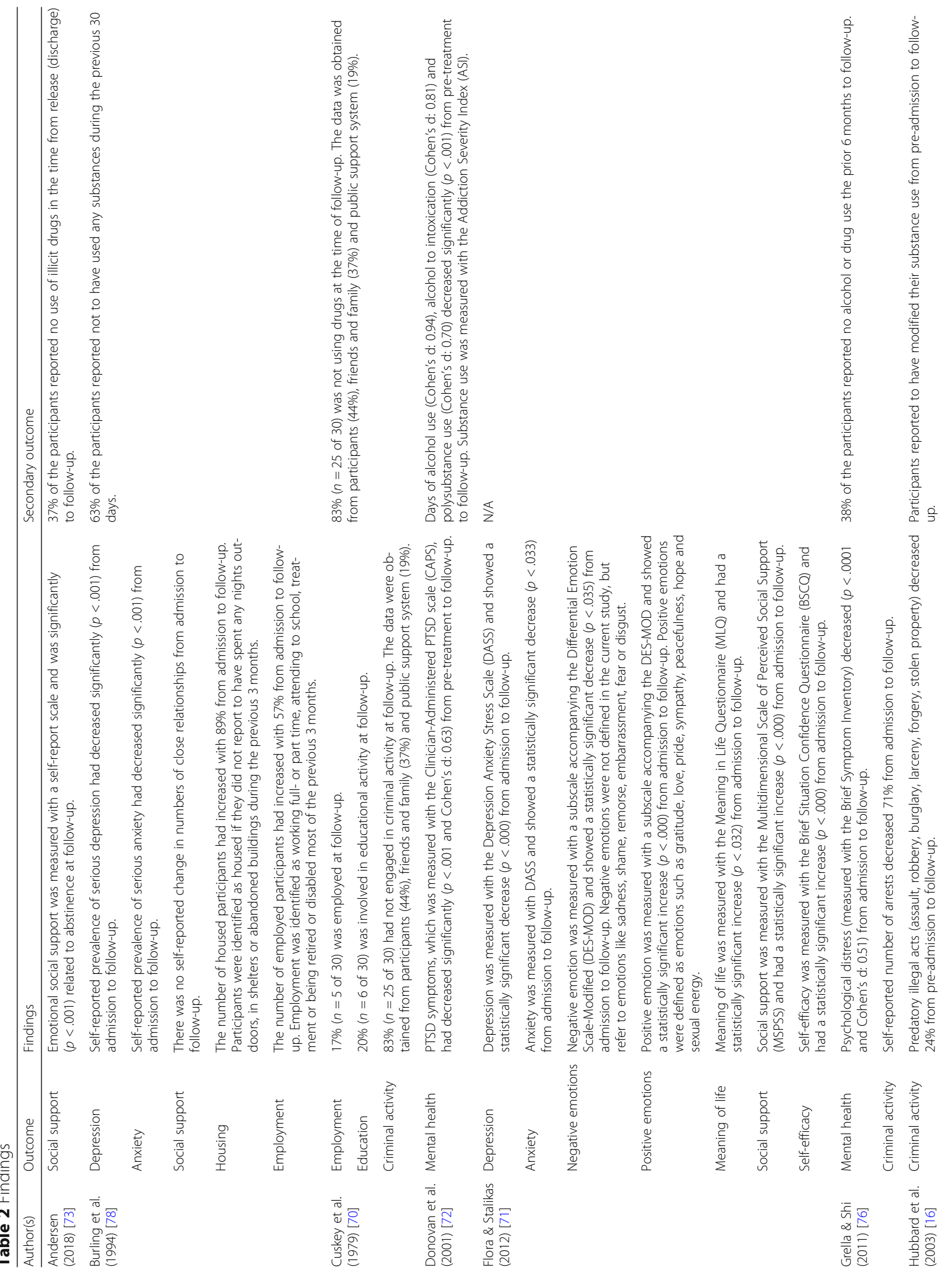




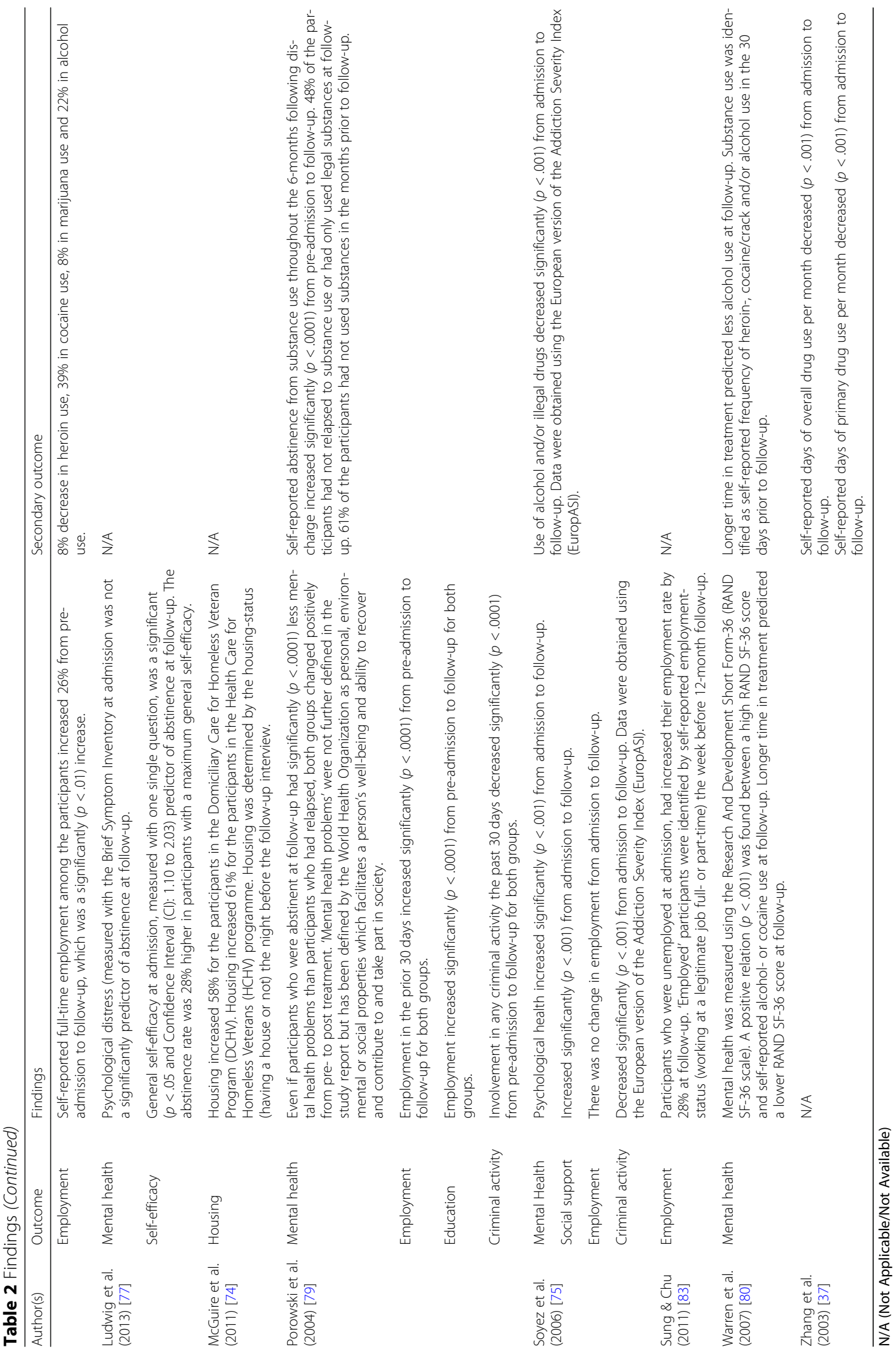


treatment was $32 \%(\mathrm{Mdn}=27 \%)$. Furthermore, one study [79] suggested a significant increase in employment from admission to follow-up, while another study [75] reported no change in employment status from admission to discharge from inpatient SUD treatment.

In addition, education was the outcome of interest in two studies [70, 79]. Findings from one study [70] suggested that $20 \%$ of the participants were involved in educational activity at follow-up, while findings from the other study [79] suggested a significant increase in educational activity from pre-treatment to follow-up.

Findings across these studies suggest an overall increase in employment and a potential increase in educational activity from admission to follow-up after inpatient SUD treatment.

\section{Criminal activity}

Five studies reported findings on engagement in criminal activity. Two of these studies [70, 76] reported the percentage of participants who had not engaged in any criminal activity from discharge to follow-up, which constitutes an $\mathrm{M}$ of $77 \%$. Next, when comparing measures from pre-treatment to measures at follow-up, one study found that criminal activity had decreased with $24 \%$ [16] and another study found a significant reduction in criminal activity [75]. One study [79] reported a significant decrease in criminal activity during the 30 days prior to follow-up compared to pre-admission.

Findings across these studies suggest an overall decrease in criminal activity at follow-up after inpatient SUD treatment.

\section{Social support}

Four studies reported findings related to social support. One of these [73] implied a correlation between abstinence and perceived social support at follow-up. One study [78] suggested that there was no change in close relationships from admission to follow-up after inpatient SUD treatment. Two studies [71, 75], however, reported a significant increase in social support from admission to follow-up. Social support is often operationalised as instrumental or emotional. Instrumental social support refers to properties in the support system like public services and financial aid, while emotional social support is identified as perceived interpersonal support and connectedness [84].

Findings across these studies suggest a possible, but slight, increase in perceived social support at follow-up after inpatient SUD treatment.

\section{Housing}

Together with education, housing was the least studied psychosocial factor among the included studies. Housing represented the outcome of interest in two studies [74, 78].
The number of housed participants increased by an average of $69 \%$ from admission to follow-up.

Findings from these two studies suggest an increase in housed participants from admission to follow-up after inpatient SUD treatment.

\section{Secondary outcome}

Four studies [71, 74, 77, 83] did not examine the prevalence of substance use at follow-up after inpatient SUD treatment. The remaining studies reported change in substance use from admission to follow-up. Findings from four studies [16, 37, 72, 75] suggested a decrease in substance use or an increase in abstinence at follow-up after inpatient SUD treatment. One study [79] reported both decreased substance use from admission to follow-up and the $\mathrm{M}$ percentage (55\%) of abstinent participants at follow-up. Four studies [70, 73, 76, 78] showed that both the $\mathrm{M}$ and Mdn percentage of abstinent participants at follow-up was 55\%. The last study [80] suggested a correlation between treatment duration and abstinence at follow-up after inpatient SUD treatment.

Findings from these studies suggest an overall decrease in substance use from admission to follow-up after inpatient SUD treatment.

\section{Discussion}

The current report presents findings from a systematic review of studies that have explored change in psychosocial factors connected to recovery capital after inpatient SUD treatment. Findings from 14 eligible studies have been presented.

The findings imply an overall progress in mental health, and a potential improvement in employment status and perceived social support for people who undergo inpatient SUD treatment. Additionally, they indicate a decrease in substance use from admission to follow-up after inpatient SUD treatment. Even if pre- and post-measures related to lifetime prevalence of criminal activity and criminal activity between discharge and follow-up are non-comparable values, findings suggest a decreased engagement in criminal activity at follow-up compared to pre-admission. These findings are consistent with earlier research on factors that are important when recovering from SUD, such as meaningful activity $[6,24,26-28,30,32]$, social support $[24,26-31]$ and mental health $[85,86]$.

Among the studies that took abstinence after discharge into consideration, the definitions varied. Abstinence at follow-up was defined as "no use of any substances at any time since discharge" (p. 196) by Porowski et al. [79]. Cuskey et al. [70] reported only findings related to the number of participants not using substances at follow-up, while Grella and Shi [76] explored substance use during the 6 months prior to follow-up. However, 
findings are in accordance with outcomes from previous comprehensive prospective studies showing a reduction in substance use after various modalities of SUD treatment [10, 13-15], as well as previous findings related to the proportion of participants who continue using substances after treatment [5-7].

Self-efficacy, housing, education and QoL were expected to be more prominent outcomes of interest among the included studies. Change in self-efficacy after inpatient SUD treatment was explored in only one study, Flora and Stalikas [71]. In addition, Ludwig [77] used measures of general self-efficacy to predict abstinence at follow-up and Sung and Chu [83] found self-efficacy to be a predictive factor for employment status after SUD treatment. On the other hand, previous research has identified self-efficacy as a key element related to coping with abstinence, adherence to treatment and successful recovery from SUD $[50,87,88]$. The cited studies examined changes in psychosocial factors after short-term inpatient SUD treatment as well as self-efficacy's potential influence on personal change, such as recovering from SUD.

While earlier research findings have highlighted stable housing as an essential facilitator and motivation for wage labour and abstinence from substance use [28, 89, 90], just two studies $[74,78]$ presented housing status as the outcome of interest after inpatient SUD treatment. Thus, the insight that only two studies considered housed participants as a result of interest, did not correspond with the emphasis of housing as recovery capital, found in earlier research [24, 26-31]. Previous studies have examined different aspects of housing, including how people with SUD highlighted housing as an important factor in recovery and as an important motivation and part of continued care after different SUD treatment modalities.

Educational activity appears to be a scantly investigated outcome and was only explored in two of the included studies [70, 79]. However, according to Laudet and White [90], patients in all stages of recovery underline education as highly prioritised, but also as a subject of concern during their recovery. Employment seems to play an essential role in the motivation for recovering from SUD, as reported by Manuel et al. [28]. Further, education is considered as a valuable attribute in the labour market [91], also for people who have struggled with SUD [92]. As anticipated, Sung and Chu [83] found that education predicted personal income after SUD treatment. Sustainable personal income has in turn been emphasised as a motivation to afford basic properties in everyday life as abstinence [24, 28]. Previous research on the role of education in SUD recovery, were conducted in other contexts than inpatient treatment (e.g. outpatient, shot-term inpatient, continued care), and in connection to work and employment.
One study [74] explored how QoL was associated with a set of selected values but did not present separate results for participants adhering to long-term inpatient SUD treatment. Another study [80] examined how QoL was associated with treatment duration and continued substance use after inpatient SUD treatment. Previous research, however, suggests that SUD inpatients have lower QoL compared to the general population and SUD out-patients [93, 94]. QoL appears to improve after various interventions aiming to reducing substance use [94, 95], and decrease with stressful life events [95]. Additionally, research findings imply that SUD treatment facilitate reduced substance use [8, 10, 13-15], and improved everyday function [90], even if complete abstinence is not achieved. In view of the overarching international ambition to provide SUD treatment, relapse to substance use alone may be a weak standard of successful recovery. The negotiated objective of SUD treatment is to decrease the extent of substance use as much as possible, reduce the negative consequences for the individual, and to "improve function and well-being of the affected individual" (p. 7) [1]. Bearing this in mind, factors such as QoL and substance use after SUD treatment may be a more viable combination to measure successful recovery [94, 95]. On this background, QoL was expected to be more explored as an outcome of interest after inpatient SUD treatment, than the findings from this review revealed.

Finally, approximately half of the included studies were based on data obtained from vulnerable samples. Clinical diversity in such factors across individual studies stimulate to a discussion about potential impact on validity of the final syntheses. Vulnerable groups, like those included in the current review, oftentimes tend to be excluded from clinical research $[96,97]$ and may affect the treatment outcome in a negative manner [98]. Vulnerable subjects within an already vulnerable population, which the SUD population represents, are especially exposed and represents a minority in a subordinate group in society [1]. For instance, people with co-occurring disorders are afflicted with a severe mental health condition in addition to SUD, and people who lack a permanent home lack the basic needs which are recognised as fundamental in recovering from SUD [99]. Furthermore, women are underrepresented in the SUD population [100], which makes them an especially vulnerable group in an already exposed population [1]. Arguably the exclusion of such vulnerable groups from research may affect the representativity of the body of knowledge on the SUD field.

\section{Limitations}

When interpreting findings presented in this review, it is important to take potential limitations into consideration. 
Even though all three authors have contributed throughout the planning of the procedure and the systematic search, only one author carried out the systematic search and the first screening of search results. This may serve as a gateway for selection bias, which may have influenced the final results. However, uncertainty related to choices was discussed between the authors inn all stages. The determined inclusion criteria, like the choice to only include long-term inpatient treatment or to exclusively consider studies that have applied a cohort study design, have most likely led relevant studies to be undetected in the systematic search or excluded during the screening. Still, the authors found it important to narrow the inclusion criteria to broaden the probability to find studies that could highlight the research question. Furthermore, there are aspects of the included studies that limit the opportunity to present clear-cut conclusions. For instance, across the included studies, data were mostly collected using self-reported measures. While this may serve as a limitation in some populations, findings from previous research reveal a good correspondence between self-reported substance use and biological samples like urine test or hair samples in the SUD population [16, 101-103] . Furthermore, in Porowski et al. [79] study, results concerning patient outcome were excluded from clinics that lost more than $50 \%$ of their participants to follow-up, an issue present in 18 out of 50 clinics. Additionally, Cuskey et al. [70] solely reported results from measures taken at follow-up. Finally, half of the included studies and approximately half of the participants in total, represents vulnerable groups. Even if clinical diversity is rather the rule than the exception when conducting an aggregative systematic review [104], the results and conclusions in this review are presented with caution and the findings should only be generalised if it is probable to assume that they are transferable to the current population.

\section{Conclusion}

The current review has explored change in psychosocial factors connected to recovery capital and coping behaviour in everyday life after inpatient SUD treatment. Various factors like social support, meaningful activity (e.g. employment and education), criminal activity, mental health, psychological distress and mental health problems, have been previously studied. Earlier research emphasises the importance of factors connected to recovery capital, like self-efficacy, housing, education and QoL, which facilitates the ability to cope without substance use. Nonetheless, the present study indicates that knowledge about how inpatient SUD treatment influence the latter mentioned factors seems to be faint or absent and implies a need for more research on how these factors are associated with coping behaviour after inpatient SUD treatment.
Due to the substantial resources used to provide SUD treatment, knowledge about recovery capital, like psychosocial factors that facilitate coping behaviour and reintegration to society, should be standardised and used by SUD treatment providers. The current findings may, however, also encourage a critical view on how change in the mentioned psychosocial factors are connected to inpatient treatment in favour of other potentially influential factors.

\section{Additional files}

Additional file 1: Text words used in the systematic search. (PDF $64 \mathrm{~kb}$ ) Additional file 2: Subject headings used in the systematic search in the included databases. (PDF $81 \mathrm{~kb}$ )

Additional file 3: Main search (example draft from the systematic search in Medline Ovid). (PDF 92 kb)

\section{Abbreviations}

CASP: Critical Appraisal Skills Programme; Cl: Confidence interval; DATOS: Drug Abuse Treatment Outcome Study; ICD-10: The 10th edition of the International Statistical Classification of Diseases and Related Health Problems; M: Mean; Mdn: Median; NTORS: National Treatment Outcome Research Study; PEcO: Population, exposure, outcome; PRISMA: Preferred Reporting Items for Systematic Reviews and Meta-Analyses; QoL: Quality of Life; SD: Standard deviation; SUD: Substance use disorder; TOPS: Treatment Outcome Prospective Study

\section{Acknowledgments}

We would like to acknowledge the academic librarian, Malene Wøhlk Gundersen, who contributed to the development of the search strategy and recommendations of databases relevant to the current aim.

\section{Funding}

This review is part of a PhD which is founded by Blue Cross East in Norway. Blue Cross East took no other part in the research project or the included studies.

\section{Availability of data and materials}

The data material of which this systematic review founds upon has been made available through Tables, Figures and Additional files. All or selections of the 142 completed data extraction form may be released by contacting the corresponding author.

\section{Authors' contributions}

All three authors (DAJ, TN and $A \varnothing \mathrm{G}$ ) contributed to designing the systematic search, analysing the findings and writing the review report. One author (DAJ) conducted the systematic search, screened the search results, extracted the data and preformed the CASP rating. Studies that were identified as unclear were screened by the second author (TN). The third author $(A \varnothing G)$ decided the eligibility of studies that were identified as unclear by both DAJ and TN. All authors read and approved the final manuscript.

\section{Authors' information}

The systematic review was conducted as part of the first authors PhD project at OsloMet - Oslo Metropolitan University and funded by Blu Cross East in Norway.

\section{Ethics approval and consent to participate}

The target group, people with SUD, might be considered as vulnerable. On this background, this population was the group of interest in this review of already conducted studies. Patients have not been involved in this study and an ethical approval has therefore not sought. 


\section{Competing interests}

The authors declare that they have no competing interests.

\section{Publisher's Note}

Springer Nature remains neutral with regard to jurisdictional claims in published maps and institutional affiliations.

\section{Author details}

'Blue Cross East, Oslo, Norway. ${ }^{2}$ Department of Psychology, Norwegian University of Science and Technology (NTNU), Trondheim, Norway. ${ }^{3}$ Faculty of Social Sciences, Department of Social Work, Child Welfare and Social Policy, OsloMet - Oslo Metropolitan University, Pb 4, St. Olavs plass, 0130 Oslo, Norway.

\section{Received: 13 December 2018 Accepted: 22 April 2019}

\section{Published online: 03 May 2019}

\section{References}

1. United Nations Office on drugs and crime (UNODC) and World Health Organization (WHO). International standards for the treatment of drug use disorders. 2016. https://www.unodc.org/documents/commissions/CND/CND_ Sessions/CND 59/ECN72016_CRP4 V1601463.pdf. Accessed 7 Aug 2016.

2. Gerra G, Poznyak V, McDonald R, Campello G, Busse A, Clark N, et al. The SO-S initiative -stop overdose safely - UNODC-WHO multi-site study on community management of opioid overdose, including emergency naloxone. Vienna: United Nations Office on drugs and crime (UNODC) and World Health Organization (WHO); 2017. http://www.unodc.org/documents/ UNODC_WHO_SOS_Initiative_2017.pdf. Accessed 7 Aug 2017.

3. World Health Organization (WHO). Global status report on alcohol and health 2018. 2018. https://www.who.int/substance abuse/publications/ global_alcohol_report/en/. Accessed 17 Oct 2018.

4. European Monitoring Centre for Drugs and Drug Addiction (EMCDDA). Drug treatment expenditure: a methodological overview. 2017. http://www. emcdda.europa.eu/system/files/publications/6238/TI_PUBPDF TDXD17001ENN PDFWEB 20171005172306.pdf en. Accessed 26 Oct 2017.

5. Blodgett JC, Maisel NC, Fuh IL, Wilbourne PL, Finney JW. How effective is continuing care for substance use disorders? A meta-analytic review. J Subst Abus Treat. 2014;46(2):87-97.

6. Nordfjærn T. Relapse patterns among patients with substance use disorders. J Subst Abus. 2011;16(4):313-29.

7. Hunt WA, Barnett LW, Branch LG. Relapse rates in addiction programs. J Clin Psychol. 1971:27(4):455-6.

8. Gossop M, Stewart D, Browne N, Marsden J. Factors associated with abstinence, lapse or relapse to heroin use after residential treatment: protective effect of coping responses. Addiction. 2002;97(10):1259-67.

9. World Health Organization (WHO). ICD-10 classification of mental and Behavioural disorders: clinical descriptions and diagnostic guidelines. Albany: World Health Organization; 1992.

10. Gossop M, Marsden J, Stewart D, Edwards C, Lehmann P, Wilson A, et al. The National Treatment Outcome Research Study in the United Kingdom: six-month follow-up outcomes. Psychol Addict Behav. 1997;11(4):324-37.

11. Kasarabada ND, Anglin MD, Khalsa-Denison E, Paredes A. Differential effects of treatment modality on psychosocial functioning of cocaine-dependent men. J Clin Psychol. 1999;55(2):257-74.

12. Group PMR. Matching patients with alcohol disorders to treatments: clinical implications from project MATCH. J Ment Health. 1998;7(6):589-602.

13. Leshner Al, Curry SJ, Simpson DD. Introduction to the special issue: the National Institute on Drug Abuse's (NIDA's) drug abuse treatment outcome study (DATOS). Psychol Addict Behav. 1997:11(4):211-5.

14. Gossop M, Marsden J, Stewart D, Rolfe A. Patterns of drinking and drinking outcomes among drug misusers: 1-year follow-up results. J Subst Abus Treat. 2000;19(1):45-50.

15. Gossop M, Marsden J, Stewart D, Rolfe A. Patterns of improvement after methadone treatment: 1 year follow-up results from the National Treatment Outcome Research Study (NTORS). Drug Alcohol Depend. 2000;60(3):275-86

16. Hubbard RL, Craddock SG, Anderson J. Overview of 5-year followup outcomes in the drug abuse treatment outcome studies (DATOS). J Subst Abus Treat. 2003:25(3):125-34.

17. Hubbard RL, Rachal JV, Craddock SG, Cavanaugh ER. Treatment outcome prospective study (TOPS): client characteristics and behaviours before, during, and after treatment. NIDA Res Monogr. 1984;51:42-68.
18. Gossop M. Treatment outcomes: what we know and what we need to know. London: London National Treatment Agency for substance misuse; 2005

19. Lauritzen G, Nordfjærn T. Changes in opiate and stimulant use through 10 years: the role of contextual factors, mental health disorders and psychosocial factors in a prospective SUD treatment cohort study. PLoS One. 2018;13(1):1-16.

20. Granfield R, Cloud W. Coming clean: overcoming addiction without treatment. New York: New York University Press; 1999.

21. Groshkova T, Best D, White W. The assessment of Recovery capital: properties and psychometrics of a measure of addiction recovery strengths. Drug Alcohol Rev. 2013;32(2):187-94.

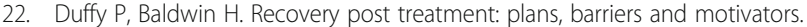
Subst Abuse Treat Prev Policy. 2013;8(1):6.

23. Cloud W, Granfield R. Conceptualizing Recovery capital: expansion of a theoretical construct. Subst Use Misuse. 2008;43(12-13):1971-86.

24. Neale J, Tompkins C, Wheeler C, Finch E, Marsden J, Mitcheson L, et al. "You're all going to hate the word recovery by the end of this": service users' views of measuring addiction recovery. Drugs Educ Prev Policy. 2015; 22(1):26-34

25. Skinner EA, Edge K, Altman J, Sherwood H, Cooper H. Searching for the structure of coping: a review and critique of category Systems for Classifying Ways of coping. Psychol Bull. 2003;129(2):216-69.

26. Neale J, Finch E, Marsden J, Mitcheson L, Rose D, Strang J, et al. How should we measure addiction recovery? Analysis of service provider perspectives using online Delphi groups. Drugs Educ Prev Policy. 2014;21(4):310-23.

27. Bergman BG, Hoeppner BB, Nelson LM, Slaymaker V, Kelly JF. The effects of continuing care on emerging adult outcomes following residential addiction treatment. Drug Alcohol Depend. 2015;153:207.

28. Manuel JI, Yuan Y, Herman DB, Svikis DS, Nichols O, Palmer E, et al. Barriers and facilitators to successful transition from long-term residential substance abuse treatment. J Subst Abus Treat. 2017:74:16-22.

29. Spear S, Crevecoeur-MacPhail D, Denering L, Dickerson D, Brecht M-L. Determinants of successful treatment outcomes among a sample of urban American Indians/Alaska natives: the role of social environments. Official publication of the National Council for. Community Behav Healthc. 2013; 40(3):330-41.

30. Von Greiff N, Skogens L. Förändringsprocesser i samband med missbruksbehandling - vilka faktorer beskriver klienter som viktiga för att initiera och bibehålla positiva förändringar? Change processes connected to substance abuse treatment - which factors do clients describe as important for initiating and maintaining positive changes? Nordisk alkohol- og narkotikatidsskrift (NAT). 2012:29(2):195-209.

31. Pettersen $H$, Landheim A, Skeie I, Biong S, Brodahl M, Benson V, et al. Why do those with long-term substance use disorders stop abusing substances? A qualitative study. Subst Abuse Res Treat. 2018. https://doi.org/10.1177/ 1178221817752678

32. Decker K, Peglow S, Samples C, Cunningham T. Long-term outcomes after residential substance use treatment: relapse, morbidity, and mortality. Mil Med. 2017. https://doi.org/10.7205/MILMED-D-15-00560.

33. Proctor S, Wainwright J, Herschman P. Patient adherence to multicomponent continuing care discharge plans. J Subst Abus Treat. 2017;80:52

34. Andersson HW, Wenaas M, Nordfjaern T. Relapse after inpatient substance use treatment: a prospective cohort study among users of illicit substances. Addict Behav. 2019:90:222.

35. Brunette MF, Drake RE, Woods M, Hartnett T. A comparison of long-term and short-term residential treatment programs for dual diagnosis patients. Psychiatr Serv. 2001;52(4):526-8.

36. Hubbard RL, Craddock SG, Flynn PM, Anderson J, Etheridge RM, Curry SJ, et al. Overview of 1-year follow-up outcomes in the drug abuse treatment outcome study (DATOS). Psychol Addict Behav. 1997;11(4):261-78.

37. Zhang Z, Friedmann PD, Gerstein DR. Does retention matter? Treatment duration and improvement in drug use. Addiction. 2003;98(5):673-84.

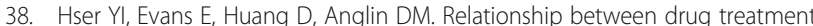
services, retention, and outcomes. Psychiatr Serv. 2004;55(7):767-74.

39. National Institute on Drug Abuse (NIDA). Principles of drug addiction treatment: a research-based guide: National Institute of drug abuse. 2018. Available from: https://www.drugabuse.gov/publications/principles-drugaddiction-treatment-research-based-guide-third-edition

40. European Monitoring Centre for Drugs and Drug Addiction (EMCDDA). Residentia treatment for drug use in Europe. Luxenbourg: EMCDDA papers; 2014. 
41. Donmall M, Jones A, Weston S, Davies L, Hayhurst KP, Millar T. The drug treatment outcomes research study (DTORS): research design and baseline data. Open Addict J. 2012;5:1-11.

42. Comiskey CM, Kelly PJ, Leckey Y, McCulloch L, O'Duill B, Stapleton RD, et al. The ROSIE study: drug treatment outcomes in Ireland. Dublin: National Advisory Committee on drugs; 2009.

43. Andrew Jones, Michael Donmall, Tim Millar, Alison Moody, Samantha Weston, Tracy Anderson, et al. The drug treatment outcomes research study (DTORS): final outcomes report. 2009.

44. Flynn PM, Craddock SG, Hubbard RL, Anderson J, Etheridge RM, Curry SJ, et al. Methodological overview and research Design for the Drug Abuse Treatment Outcome Study (DATOS). Psychol Addict Behav. 1997; 11(4):230-43.

45. Salwan J, Katz CL. A review of substance use disorder treatment in developing world communities. Ann Glob Health. 2014;80(2):115-21.

46. Gough DA, Oliver S, Thomas J. An introduction to systematic reviews. Second ed. London: SAGE; 2017.

47. Glasziou P, Del Mar C, Salisbury J. Evidence-based practice workbook: bridging the gap between health care research and practice. 2nd ed. Malden: Blackwell/BMJ; 2007.

48. Liberati A, Altman DG, Tetzlaff J, Mulrow C, Gøtzsche PC, loannidis JPA, et al. The PRISMA statement for reporting systematic reviews and meta-analyses of studies that evaluate health care interventions: explanation and elaboration. Ann Intern Med. 2009;151(4):65-94.

49. Critical Appraisal Skills Programme. CASP cohort study checklist. 2018. Available from: https://casp-uk.net/wp-content/uploads/2018/01/CASPCohort-Study-Checklist.pdf.

50. Levin C, Ilgen M, Moos R. Avoidance coping strategies moderate the relationship between self-efficacy and 5-year alcohol treatment outcomes. Psychol Addict Behav. 2007;21(1):108-13.

51. Pasareanu AR, Vederhus JK, Opsal A, Kristensen O, Clausen T. Mental distress following inpatient substance use treatment, modified by substance use; comparing voluntary and compulsory admissions. BMC Health Serv Res. 2017;17(1):5.

52. Teesson M, Mills K, Ross J, Darke S, Williamson A, Havard A. The impact of treatment on 3 years' outcome for heroin dependence: findings from the Australian treatment outcome study (ATOS). Addiction. 2008;103(1):80-8.

53. Gossop M, Marsden J, Stewart D, Treacy S. Change and stability of change after treatment of drug misuse. 2-year outcomes from the National Treatment Outcome Research Study (UK). Addict Behav. 2002;27(2):155-66.

54. Wakeman SE, Metlay JP, Chang Y, Herman GE, Rigotti NA. Inpatient addiction consultation for hospitalized patients increases post-discharge abstinence and reduces addiction severity. J Gen Intern Med. 2017;32(8):909-16.

55. Wagner T, Krampe H, Stawicki S, Reinhold J, Jahn H, Mahlke K, et al. Substantial decrease of psychiatric comorbidity in chronic alcoholics upon integrated outpatient treatment - results of a prospective study. J Psychiatr Res. 2004;38(6):619-35.

56. Norwegian Directorate of Health. Guideline for prioritisation in specialised treatment for substance use disorder. 2015.

57. Norwegian Directorate of Health. National guidelines for treatment and rehabilitation of substance dependency. 2015.

58. Simpson DD, Joe GW, Fletcher BW, Hubbard RL, Anglin MD. A National Evaluation of treatment outcomes for cocaine dependence. Arch Gen Psychiatry. 1999;56(6):507-14.

59. Monahan SC, Finney JW. Explaining abstinence rates following treatment for alcohol abuse: a quantitative synthesis of patient, research design and treatment effects. Addiction. 1996;91(6):787-805.

60. Tanner-Smith EE, Wilson SJ, Lipsey MW. The comparative effectiveness of outpatient treatment for adolescent substance abuse: a meta-analysis. J Subst Abus Treat. 2013;44(2):145-58.

61. McCarty D, Braude L, Lyman DR, Dougherty RH, Daniels AS, Ghose SS, et al. Substance abuse intensive outpatient programs: assessing the evidence. Psychiatr Serv (Washington, DC). 2014;65(6):718-26

62. Penzenstadler L, Machado A, Thorens G, Zullino D, Khazaal Y. Effect of case management interventions for patients with substance use disorders: a systematic review. Frontiers Psych. 2017;8:51.

63. Watson JM, Fayter D, Mdege N, Stirk L, Sowden AJ, Godfrey C. Interventions for alcohol and drug problems in outpatient settings: a systematic review. Drug Alcohol Rev. 2013;32(4):356-67.

64. Mørland J, Waal H. Rus og avhengighet [Substance and dependency]. Oslo: Universitetsforl; 2016
65. Black N. Why we need observational studies to evaluate the effectiveness of health care. BMJ. 1996;312(7040):1215-8.

66. Mann CJ. Observational research methods. Research design II: cohort, cross sectional, and case-control studies. Emerg Med J. 2003;20(1):54.

67. Morgenstern J, McKay JR. Rethinking the paradigms that inform behavioral treatment research for substance use disorders. Addiction. 2007;102(9):1377-89.

68. Gupta A, Thorpe C, Zwarenstein M. Why most randomized controlled trials are irrelevant: and why yours will not be. Can Fam Physician Medecin de famille canadien. 2015;61(9):811-2.

69. Moher D, Shamseer L, Clarke M, Ghersi D, Liberati A, Petticrew M, et al. Preferred reporting items for systematic review and meta-analysis protocols (PRISMA-P) 2015 statement. Syst Rev. 2015;4:1.

70. Cuskey WR, Richardson AH, Bergen LH, Odyssey H. Specialized therapeutic community program for female addicts. Washington: National Institute on Drug Abuse (NIDA); 1979.

71. Flora K, Stalikas A. Factors affecting substance abuse treatment in Greece and their course during therapy. Addict Behav. 2012;37(12):1358-64.

72. Donovan B, Padin-Rivera E, Kowaliw S. "Transcend": initial outcomes from a posttraumatic stress disorder/substance abuse treatment program. J Trauma Stress. 2001;14(4):757-72.

73. Andersen TS. Social support and one-year outcomes for women participating in prison-based substance abuse treatment programming. Crim Justice Stud. 2018;31(1):80-94.

74. McGuire J, Rosenheck RA, Kasprow WJ. Patient and program predictors of 12-month outcomes for homeless veterans following discharge from timelimited residential treatment. Adm Policy Ment Health Ment Health Serv Res. 2011;38(3):142-54.

75. Soyez $V$, Broekaert $E$, Rosseel $Y$. Social network involvement during therapeutic community treatment: is there an impact on success? Ther Communities. 2006;27(1):45-67.

76. Grella CE, Shi Y. Stability of outcomes following residential drug treatment for patients with co-occurring disorders. J Dual Diagn. 2011;7(1-2):103-12

77. Ludwig F, Tadayon-Manssuri E, Strik W, Moggi F. Self-efficacy as a predictor of outcome after residential treatment programs for alcohol dependence: simply ask the patient one question. Alcohol Clin Exp Res. 2013;37(4):663-7.

78. Burling TA, Seidner AL, Salvio MA, Marshall GD. A cognitive-behavioral therapeutic community for substance dependent and homeless veterans: treatment outcome. Addict Behav. 1994;19(6):621-9.

79. Porowski AW, Burgdorf K, Herrell JM. Effectiveness and sustainability of residential substance abuse treatment programs for pregnant and parenting women. Eval Program Plann. 2004;27(2):191.

80. Warren JI, Stein JA, Grella CE. Role of social support and self-efficacy in treatment outcomes among clients with co-occurring disorders. Drug Alcohol Depend. 2007:89(2-3):267-74.

81. World Health Organozation (WHO). Mental health: a state of well-being. 2014. https://www.who.int/features/factfiles/mental_health/en/. Accessed 22 Feb 2019.

82. Bandura A. Self-efficacy. In: Ramachaudran VS, editor. Encyclopedia of human behavior. New York: Academic Press; 1994. p. 71-81.

83. Sung HE, Chu D. The impact of substance user treatment participation on legal employment and income among probationers and parolees. Subst Use Misuse. 2011;46(12):1523-35.

84. Langford CPH, Bowsher J, Maloney JP, Lillis PP. Social support: a conceptual analysis. J Adv Nurs. 1997;25(1):95-100.

85. Polcin D, Korcha R, Gupta S, Subbaraman MS, Mericle AA. Prevalence and trajectories of psychiatric symptoms among sober living house residents. J Dual Diagn. 2016;12(2):175-84.

86. Mericle AA, Cacciola J, Carise D, Miles J. Supporting recovery in the community: six-month outcomes of clients participating in the Phoenix house Bronx community recovery center (BCRC). J Community Psychol. 2014;42(5):509-18.

87. Kelly JF, Greene M. Where there's a will there's a way: a longitudinal investigation of the interplay between recovery motivation and self-efficacy in predicting treatment outcome. Psychol Addict Behav. 2014;28(3):928-34.

88. Bandura A. A Sociocognitive analysis of substance abuse: an agentic perspective. Psychol Sci. 1999;10(3):214-7.

89. Polcin DL, Korcha RA, Bond J, Galloway G. Sober living houses for alcohol and drug dependence: 18-month outcomes. J Subst Abus Treat. 2010;38(4): 356-65.

90. Laudet $A B$, White $W$. What are your priorities right now? Identifying service needs across recovery stages to inform service development. J Subst Abus Treat. 2010;38(1):51-9. 
91. The Organisation for Economic Co-operation and Development (OECD). Education at a glance 2014: highlights: OECD Publishing; 2014. https://doi. org/10.1787/eag_highlights-2014-en. Accessed 6 Aug 2018

92. Dale-Perera A. Recovery, reintegration, abstinence, harm reduction: the role of different goals within drug treatment in the European context: EMCDDA drugs library: European monitoring Centre for Drugs and Drug Addiction; 2017. http://www.emcdda.europa.eu/system/files/attachments/6322/ EuropeanResponsesGuide2017_BackgroundPape-Recovery-ReintegrationAbstinence-Harm-reduction.pdf.

93. Garg N, Yates WR, Jones R, Zhou M, Williams S. Effect of gender, treatment site and psychiatric comorbidity on quality of life outcome in substance dependence. Am J Addict. 1999;8(1):44-54.

94. Vederhus J-K, Birkeland B, Clausen T. Perceived quality of life, 6 months after detoxification: is abstinence a modifying factor? Qual Life Res Int J Qual Life Asp Treat Care Rehab. 2016:25(9):2315-22.

95. Frischknecht U, Sabo T, Mann K. Improved drinking behaviour improves quality of life: a follow-up in alcohol-dependent subjects 7 years after treatment. Alcohol Alcohol. 2013;48(5):579-84.

96. Bonevski B, Randell M, Paul C, Chapman K, Twyman L, Bryant J, et al. Reaching the hard-to-reach: a systematic review of strategies for improving health and medical research with socially disadvantaged groups. BMC Med Res Methodol. 2014;14:42.

97. Finnegan $M, O^{\prime}$ Donoghue B. Rethinking vulnerable groups in clinical research. Ir J Psychol Med. 2019;36(1):63-71.

98. Compton WM, Cottler LB, Jacobs JL, Ben-Abdallah A, Spitznagel EL. The role of psychiatric disorders in predicting drug dependence treatment outcomes. Am J Psychiatr. 2003;160(5):890-5.

99. Sumnall $H$, Brotherhood A. Social reintegration and employment: evidence and interventions for drug users in treatment. Luxemburg: European monitoring Centre for Drugs and Drug Addiction (EMCDDA); 2012.

100. United Nations Office on Drugs and Crime (UNODC). World drug report 2018. New York: The United Nations Office on Drugs and Crime (UNODC); 2018.

101. Secades-Villa R, Fernández-Hermida JR. The validity of self-reports in a follow-up study with drug addicts. Addict Behav. 2003;28(6):1175-82.

102. Simpson DD, Joe GW, Broome KM. A national 5-year follow-up of treatment outcomes for cocaine dependence. Arch Gen Psychiatry. 2002;59(6):538-44.

103. Wish ED, Hoffman JA, Nemes $S$. The validity of self-reports of drug use at treatment admission and at followup: comparisons with urinalysis and hair assays. Natl Inst Drug Abuse Res Monogr. 1997;167:200-26.

104. Deeks JJ, Higgins JP, Altman DG. Analysing data and undertaking metaanalyses. In: Cochrane handbook for systematic reviews of interventions. Version 5.1.0 (updated March 2011). The Cochrane Collaboration. http:// training.cochrane.org/handbook. Accessed 10 Apr 2019.

\section{Ready to submit your research? Choose BMC and benefit from:}

- fast, convenient online submission

- thorough peer review by experienced researchers in your field

- rapid publication on acceptance

- support for research data, including large and complex data types

- gold Open Access which fosters wider collaboration and increased citations

- maximum visibility for your research: over $100 \mathrm{M}$ website views per year

At $\mathrm{BMC}$, research is always in progress.

Learn more biomedcentral.com/submissions 